\title{
Gozo Yoshimasu
}

\section{TAттоO}

A new shadow for my soul. Behind my dream, a young tree quietly falls.

Although I am a shadow of a passenger on this planet, my soul is always absorbed in play. Whose voice?-I wanted a tattoo.

Yura yura (sway-ing, sway-ing) I, also, (a young tree) with sleepy eyes, the remnants of the garden's light, my eyes dreamed. The voice came from behind the temple. A pearl began to speak softly. I fell down.

In a dream the tenor's eyes lit up. The serpent stands and walks away. The smell of apples.

Don't you think the moon is wet? Deep in the dream, the gate's lock whispered: yes, then a dragonfly will make the trip. Loaded down with panes of glass, discarded treasures, things that shine. A dragonfly was flying to the moon.

\section{Santa Fe Railroad Lemy Station}

Twilight, a deserted station, the Santa Fe Railroad, we stood at Lemy Station. There was a thicket of bushes and an old Cheyenne, sitting. (Or he wasn't there at all. My memory has a thicket of bushes, an old Cheyenne, sitting.) — When, I heard, it, a clear day in autumn, twilight, a deserted station, the Santa Fe Railroad, we stood at Lemy Station. The Rio Grande, a deep crevice, long ago, the Indian children played, chasing squirrels and weasels. On snowy days, the Rio Grande, makes the crevice deeper. A clear autumn day, there's a clock in the station, (I don't know) the 
schedule, the Santa Fe Railroad, we stood at Lemy Station. Across the Rio Grande, a white building, a mad house stands, across the Rio Grande, a deep crevice. A thicket, (beside) the bushes, we sat down, doing simple calisthenics: one, two, three, right? This world, is a giant, hospital. Hey boy with the long shadow, a walnut cave, hey chipmunk from Yatsugatake, hey squirrel, you pulled me along, we've circled the sun once already. I raced the gears (or was it an automatic?). That day, an autumn day, twilight, a deserted station, the Santa Fe Railroad, we stood at Lemy Station.

There

was a thicket of bushes, an old Cheyenne, sitting. (Or he wasn't there at all. My memory has a thicket of bushes, an old Cheyenne, sitting.) In drunken exile, from an adobe house, from the reservation. (Or he wasn't there at all. My memory has a thicket of bushes, an old Cheyenne, sitting.) We are living fossils, hey chipmunk from Yatsugatake, hey squirrel, the Sioux, the Hopi. The chipmunk, chewed, a splendid nest. A mud house, covered in mud, a mad house, dressed in white (there are colored robes too). We, are, living fossils, yes, man is mortal. We, are, post-war, in the crevice, of, mortality. Any vacancies? To Taos/Pueblo, (getting out of our car) on a trail, walking, thinking (the tape won't go around, this trail, on snowy days). Thinking. Walking on a trail, that, winds around like a pitcher's form, do you know what I mean? We walked.

The Rio

Grande, a deep crevice, long ago. The Indian children played, chasing squirrels and weasels. Some day, we may become, people, (getting out of our cars) living like Eskimos, in igloos, walking. At last, in exile. (Left for dead, on the side of a road, like an, American car, with the license plates still on. Do you know what I mean?) And then the Rio Grande, a deep crevice. The Rio Grande is a living fossil.

It flew over from / the Yucatan / Peninsula

/ a Congolese Macaw / holding up / a giant

/ feather / step / step / step

/ Macaw / Macaw / white

/ is / knowledge / black

/ is / chaos / green 


\section{/ is / the trees / of flora / red \\ / is / the blood / of / man and beasts \\ / Macaw / Macaw / Macaw / Macaw}

Macaws and parrots, be, come, speakers of, human words (sacred tongues).

In self-defense, they hold up, the giant

feather, step (a beautiful side step), step, step. ...........

Hey Macaw, Macaw

Hey Parrot, Parrot

One language may kill off another. We are, living fossils. In step, rhythm, step, step, sometimes, a language will kill off another. We, begin our migration, to another family of words. We are, fossils, of words. The sun comes shining down, hey you people, walking in Nakano, near the Tetsugaku-do. Some people, ride a wheel chair, there are, the blue sky roots, the sun, comes shining down, shaking like a body, hey you people, walking in Nakano, near the Tetsugaku-do. (Or rather, hey you chipmunks, hey you squirrels, hopping on the surface, of the planet.)

Macaw, Macaw

With eyes, slightly blackened, hey you people from the Jamon period, near the Indian reservation, looking down from the high hills, a single family, waving, lonely. (Do you know what I mean?) In a coma, a woman, as though from the pages of Penthouse, do you know what I mean? - we are, sad, with our not-so-clean Chrysler, painted white, (even if it were a new car), could we be facing, the end, of our planet? Of course, with the macaws and parrots (when the time comes, Exxon Corporation, will you save us, please?)——You came down, from a mountain top, in San Francisco, you said, Kachina doll, will you save us, please? —-Near Santa Fe, San Ildefonso village, we watched, a harvest prayer, a harvest dance, feeling sad. Even we, don't know, why. — Sadness is contagious, like a whisper, that's why. "Standard Chevron, are, you, watching, the dance?"

Macaw, Macaw,aw

Indian dolls, will, you, save us, please? At last, twilight approaches, the sun, slowly, sinks. That, earth, step, rhythm, one foot, plant, the roots, are thrown all over, we, are lined up, like a row of dolls, are thrown all over, the setting sun, sinks, watching, the sky roots, we drive, to Lemy Station, on the Santa Fe Railroad. 
Yes,

twilight, a deserted station, the Santa Fe Railroad, we stood at Lemy Station. There was a thicket of bushes and an old Cheyenne, sitting. (or he wasn't there at all. My memory has a thicket of bushes, an old Cheyenne, sitting.) — When, I heard, it, a clear day in autumn, twilight, a deserted station, the Santa Fe Railroad, we stood at Lemy Station. Even if we retire, the bolts that hold the rails, are old, or if we're drunk, we can only drive straight, (do you know what I mean?) At last, the crossings, are all gone. On TV, the stories of, the over-aged train engineers, the union got a bad deal.

Finally, twilight, approaches, the old Cheyenne, stands up. - (He said, he doesn't know how, to call the rain, to use a wizard's art), but pointing, looking from the back of his eyes, several seconds, he stood up. The Rio Grande, a deep crevice, long ago, the Indian children played, chasing squirrels and weasels. On snowy days, the Rio Grande, makes the crevice deeper. A clear autumn day -

\section{We also, stand up}

doing simple calisthenics. Where shall we go? Reading palms, straining our ears, we don't know, holding hands, do more calisthenics (when we get back, let's wash the car ...), thinking, alone, that's what it was. Hey chipmunk, hey squirrel, still, chewing and chewing and chewing on your walnuts? Hey boys, hey girls, there's already snow in the mountains.

Translated by Richard Arno 